\title{
Construction of Take-out Tableware Recycling System Based on Circular Economy Theory
}

\author{
Yuli Zhong ${ }^{1}$, Kaining Meng ${ }^{2}$, Fuxi Ouyang ${ }^{3}$ \\ ${ }^{1}$ School of Art and Design, Xihua University, Chengdu, Sichuan, 610039, China \\ ${ }^{2}$ School of Art and Design, Xihua University, Chengdu, Sichuan, 610039, China \\ ${ }^{3}$ School of Art and Design, Xihua University, Chengdu, Sichuan, 610039, China
}

\begin{abstract}
With the rapid development of China's takeaway industry, takeaway packaging waste is increasing day by day, and the environmental pollution problems caused by it cannot be ignored. In order to reduce the environmental pollution caused by take-out packaging, improve the utilization rate of resources, and achieve sustainable development of the take-out industry, on the premise of analyzing the current status and problems of the recycling of overseas sales packaging, we try to construct take-out packaging based on the $3 \mathrm{R}$ principle of circular economy theory Recycling system, and point out some basic conditions and guarantee measures that the packaging recycling system needs to meet in order to maximize the economic and social benefits of take-out packaging recycling . The first section in your paper
\end{abstract}

\section{Introduction}

Take-out services rely on the Internet, a huge information platform, to provide consumers with rich take-out information and convenient take-away services, so that consumers can enjoy take-away food without going out. Although the rapid development of the takeaway industry has brought convenience to people's daily lives, the resulting takeaway packaging waste cannot be ignored.

Meituan, a takeaway company, CEO Wang Xing posted a Weibo at the end of July 2019, saying that Meituan 's daily delivery volume has exceeded 30 million. According to the analysis report on the takeaway industry data released by iMedia Consulting 2019, Meituan ranked first in the industry, accounting for $51.8 \%$ of Eleme, another takeaway company, ranking second with a market share of $47.4 \%$, and other platforms together account for only $0.8 \%$. According to this calculation, the total daily orders for major takeaway platforms have exceeded 50 million orders.

Researchers sent questionnaires to consumers through the Internet and learned that the most commonly used takeaway packaging materials is plastic, accounting for $83.33 \%$, and most of the takeaway packaging is thrown into the trash after eating, accounting for $91.67 \%$. Only $8.34 \%$ of consumers will take out packaging for separate recycling. Therefore, the huge order volume means huge disposable plastic consumables and severe environmental pollution. Therefore, it is very serious to solve the pollution problem of takeaway packaging.

\section{Research Status}

The research on circular economy theory started earlier in foreign countries, and the research on the recycling of waste items has been relatively mature. Barry Commoner believes that the development of a circular economy must prevent environmental pollution from the source, and source prevention is more important than end-of-line governance. Eric Davidson believes that the role of government in the development of a circular economy is crucial. It can reward or punish consumers and producers through legal and tax measures, and improve the public's circular economy through education. awareness Based on the theory of circular economy, Quanxiao Pan et al. Studied the circular economy industrial chain. Through empirical research, it was found that waste products generated by highly polluting companies can be used to process and recycle waste products of relevant enterprises. Regarding the recycling system and recycling logistics, L. G DEBO and others proposed three types of recycling logistics. One is that the manufacturer is responsible for product recycling, the other is that the retailer is the product recycling point, and the third is that the third-party logistics is responsible for recycling. Zou Xiao et al. Analyzed the current status and system of express packaging recycling by using the theory of circular economy to build a recycling system for express packaging waste in China.

Compared with foreign studies on the theory of circular economy and the recycling system of waste items, domestic researches on the theory of circular economy and the recycling of waste items is still in its infancy, and a complete theoretical system has not yet

\footnotetext{
*Corresponding author's e-mail: 1044425001@qq.com
} 
been formed. Circular economy theory is currently used in a wider range of industries such as tourism, pharmaceutical industry, and high energy consumption manufacturing. However, in China, because e-commerce started late and the takeaway industry has only developed in recent years, the application of circular economy theory in the field of waste packaging recycling in the takeaway industry is still blank.

\section{Problems in the recycling of packaging waste in the takeaway industry}

\subsection{An effective take-out packaging recycling system has not been established}

The status of take-away packaging in China is shown in Figure 1. Due to the different quality of take-out packaging, and generally mixed with domestic garbage and oil pollution, low recycling profits and high processing costs, the main treatment methods now are landfill and incineration. However, landfill will occupy a lot of land resources and affect the soil and groundwater environment; incineration will generate toxic and harmful gases, which will adversely affects the atmospheric environment. Most consumers throw them into the trash after eating take-out. Even if some people realize that take-away garbage pollutes the environment, there is no environmentally-friendly take-away garbage recycling treatment method. It can be seen that China has not yet established an effective take-out packaging recycling system.

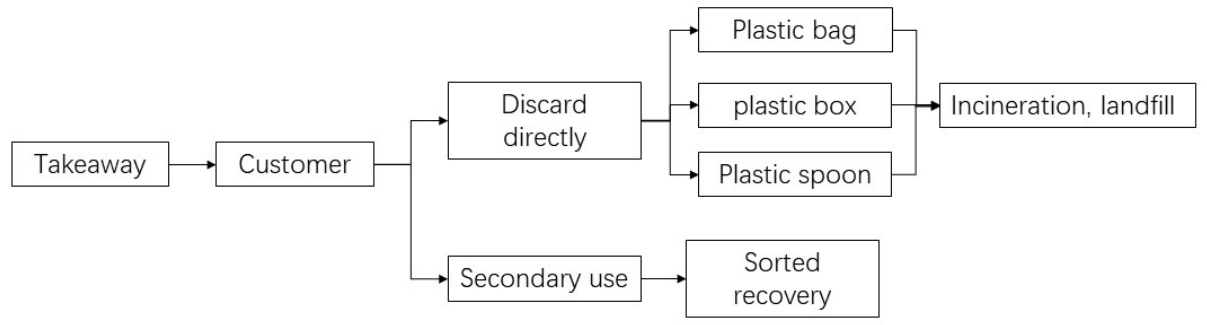

Figure 1. Main disposal methods for takeaway garbage

\subsection{Packaging materials have hidden dangers and lack of uniform standards}

As shown in Figure 2, In the process of using takeaway packaging, the decision maker of takeaway packaging is the majority of merchants. Due to the difference in the level and type of merchants, the diversification and complexity of takeaway packaging have also resulted. In addition, most of the merchants ' purchases channels purchase disposable packaging boxes from wholesalers, online shopping and other channels. Because there is no effective supervision mechanism, the packaging purchased by these merchants have great security risks.

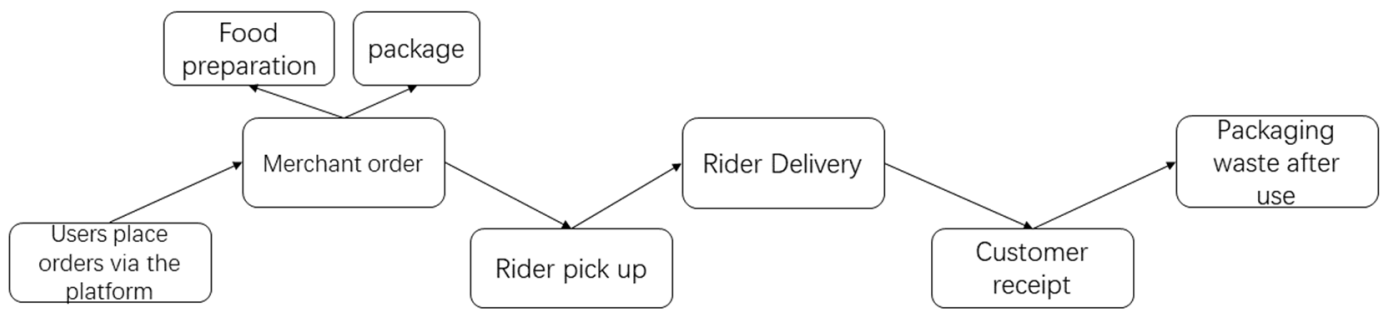

Figure 2. Flowchart of takeaway packaging

\subsection{Weak awareness of companies and consumers in recycling}

On the corporate side, although major takeaway platforms have successively introduced the option of " no tableware required ", They have had little effect. In order to avoid customer negative reviews, some customers will still receive disposable tableware even if they choose the option of no tableware required. It can be seen that companies ' efforts to protect the environment are very limited. On the consumer side, because there is no effective recycling mechanism, and the implementation of waste separation and recycling advocated by the state is very difficult, most of the takeaway waste is directly thrown into the trash bin without treatment, and the awareness of takeaway waste recycling is weak.

\subsection{Laws, regulations and supervision mechanisms for the takeaway industry are not yet perfect}

The cost of social pollution caused by takeaway garbage should be implemented by manufacturers, takeaway platforms, catering companies and consumers who produce takeaway tableware. China's producer responsibility extension system adopts a recycling model that emphasizes the producer as the mainstay, and is supplemented by sellers, consumers, and disposal companies. Establishing a comprehensive producer 
responsibility extension system is the key to solving the problem of pollution from takeaway garbage. Lift Adhering to the principle of " who pollutes and governs " makes the responsible subjects more clear, and it is necessary to establish a strong supervision mechanism and use national policies and guidelines to promote the takeaway industry to develop in an ecological direction.

\section{Construction of take-away packaging recycling system}

\subsection{Prerequisites for system construction}

Two prerequisites for building a take-away packaging recycling system are the establishment of a recycling processing center and recyclable tableware. The main function of the center is to sort, clean, disinfect and distribute the recovered tableware. Since the recycling processing center involves packaging producers and users, the producers and users can cooperate to establish a professional recycling process center, the processing center needs to have professional technology and sufficient human resources to achieve the desired results. The government's environmental protection department needs to provide certain technical and financial support for this to ensure that the recycling center can operate effectively for a long time and provide protection for packaging recycling in the takeaway industry. The design of reusable tableware needs to follow the principle of weight reduction. Modular design can be used as a means to integrate the functions of carrying and carrying. At the same time, it must also consider the thermal insulation, shock resistance and ease of cleaning of the package.

\subsection{System Construction}

It can be seen from Figure 3 that the recycling system includes two links and two channels of production and circulation (mainly for takeaway companies, supplemented by takeaway merchants and takeaway riders). The main bodies included are government, packaging manufacturing enterprises, consumers, recycling center, etc. The items to be recycled in the recycling system include waste products generated during the production of packaging and waste packaging generated during the use of take-out packaging during circulation.

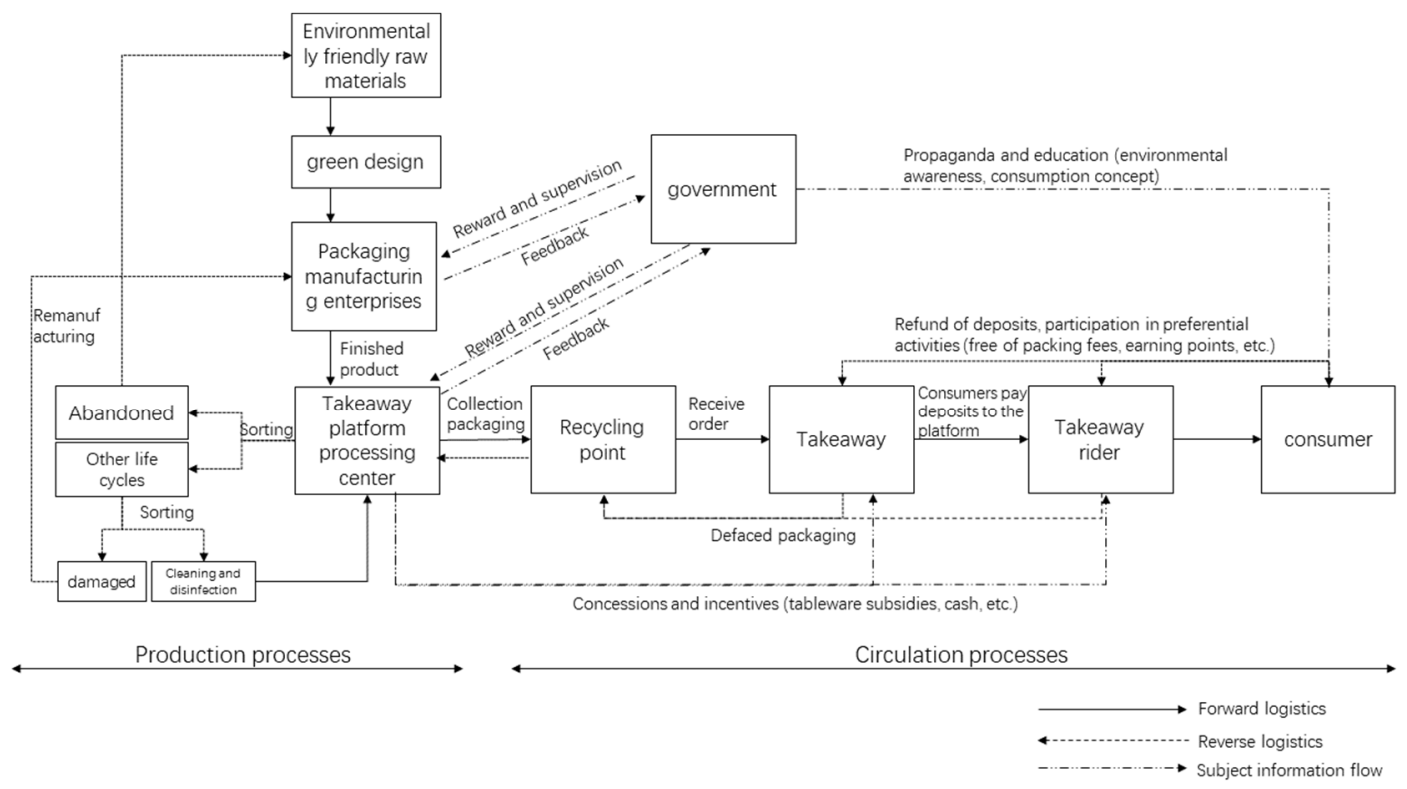

Figure 3. Takeaway packaging recycling system based on circular economy theory

\subsubsection{Production link}

At present, the materials of China's express packaging mainly include paper, plastic, foil, etc. Among them, the most frequently used disposable plastic boxes and plastic bags are the number one source of pollution. Takeaway packaging research and development enterprises need to develop scientific and reasonable packaging shapes and structures through green design according to the characteristics of the industry, thereby reducing the amount of packaging materials, comprehensively packaging various functions, rationally planning packaging placement space, and facilitating recycling, instead of traditional Courier packaging material. In the production process, take-out packaging manufacturing enterprises need to recycle the defective products and leftover materials produced into new raw materials according to the reuse principle, and some defective products can be re-manufactured into usable products. Non-recyclable materials can be disposed of in an environmentally friendly manner. The government monitors enterprises and educates consumers during the entire process. At the same time, enterprises and consumers can provide feedback to the government on related issues. 


\subsubsection{Circulation and use}

In the forward logistics stage, merchants order environmentally friendly tableware through the platform software and deliver it to the merchants from the distribution center. If consumers choose to use environmentally friendly packaging, they can waive the packaging fee and replace the tableware deposit.

The recycling system should follow the "town-level recycling-district-level processing-municipal-level management" step-by-step approach to the recovery and distribution of takeaway packaging, supplemented by the supervision of the local sanitation department. Consumers can return to packaging through riders and takeaway businesses and enter the reverse logistics cycle.

As shown in Figure 6, this recycling system addresses the problem of high labor costs and insufficient staffing for the self-recycling of packaging in the takeaway industry. It attempts to recycle the express packaging from 2 recycling channels:

Enterprises should provide incentives or incentives (tableware subsidies, cash) to riders and merchants participating in the recycling process. At the same time, they should also develop consumer incentives to encourage consumers to participate in environmental protection actions. The government needs to guide consumers with a correct view of consumption, promote the popularization of environmentally friendly tableware, and at the same time supervise the environmentally friendly tableware manufacturing and recycling processes to ensure the safety of environmentally friendly tableware.

\section{Safeguard measures}

\subsection{Government-led, supported by laws, regulations and preferential policies}

The establishment of a sound and effective recycling system requires legal constraints and corresponding market operation mechanism production guarantee. Relevant government departments should improve the laws and regulations related to the takeaway industry as soon as possible. For the issue of environmental protection of packaging materials, the relevant departments should measure the company's own emissions. The government should formulate emission standards and supporting incentives and punishment measures. And use new environmentally friendly materials to reduce emissions.

Tax policies are used to restrict responsible enterprises, so that "whoever pollutes, who controls", and give preferential tax treatment to enterprises that have done a good job in packaging recycling. On the contrary, certain fines and environmental pollution treatment costs are imposed. In addition, in order to solve the problem that the input and output of enterprises are not proportional, relevant government departments need to issue supporting preferential policies to subsidize enterprises that implement take-out packaging recycling and encourage them to recycle.

\subsection{Enterprises as the main body, regulations and $3 R$ principles as the criterion to encourage consumers to actively participate}

Enterprises should actively respond to national calls, follow industry regulations and the 3R principle of circular economy, and encourage consumers to actively cooperate to ensure the effective operation of the recycling system. Consumers' active participation is the guarantee of successful packaging recycling. Enterprises can encourage consumers to participate actively through some preferential activities. The recycling of packaging and its service life are closely related to its old and new levels. In order to ensure the effective operation of the recycling system, it is necessary to start with the packaging design. Durable and easy-to-clean materials can be used, or modular design can be used to extend the service life of the packaging. Reductions include reductions in packaging design and use. In packaging design, rationally plan the distribution space according to the actual size of the product, and minimize the use of raw materials while meeting the basic needs of customers. For different types of packaging, enterprises can set different upper limits. Consumers can return packaging and get certain rewards, coupons, cash back, points, etc. The above activities can not only motivate consumers, but also shape Good corporate social image.

\subsection{Consumers' Active Cooperation Is the Key}

Environmental protection is closely related to everyone. Ordinary consumers need to change their consumption concepts and try to accept reusable packaging and reduced packaging on the premise that the quality and hygiene of goods are guaranteed. For take-out packaging with recycling channels, you can send it to Recycling department may give recycling to recyclers; develop the habit of garbage classification, and sort takeaway packaging without special recycling channels to facilitate access to other recycling channels. Reduce the purchase of items that are not environmentally friendly and not conducive to packaging recycling.

\section{Conclusion}

Based on the 3R principle of circular economy theory, this article attempts to build a take-away packaging recycling system from the two links of production and circulation. In order to ensure the implementation of this system, the government must act as a supervisor and formulate a series of laws and regulations to restrict and educate Enterprises and consumers, improve their environmental awareness and change consumer consumption concepts, and also provide some preferential conditions for enterprises; companies should actively cooperate with the government while establishing awareness of recycling, and advocate consumers to actively cooperate with recycling Consumers should establish environmental awareness and actively cooperate with enterprises and governments. 


\section{References}

1. Commoner, B., (2002) In: Wang X., Wang W., Chen L. (Eds.), Peace with the Earth $[\mathrm{M}]$. Shanghai Translation Publishing House, Shanghai.36.

2. Davidson, E., (2003) Ins: Qi L. (Eds.), The Big Future of Ecological Economy [M]. Head University Press, Shantou. 106-120.

3. DEBO, L., SAVASKAN, R., WASSENHOVE, L., (2006) Coordination in a closed-loop supply chain [J]. Journal of Northeast University of Science and Technology (Natural Science Edition), 27 (2): 155159.

4. Pan, Q. Yu, J. Huang, C. (2012) An Empirical Study of the Pulp Sludge Industrial Cluster from the Perspective of Circular Economy Theory-Taking the "China Whiteboard Base" on Chunjiang Street, Fuyang as an example [J]. China Pulp and Paper Journal, 27 (1): 58-62.

5. Yang J., (2019) Evolutionary Game and Policy Simulation of Takeaway Waste Recovery and Treatment [D]. China University of Mining and Technology.

6. Shuang H., Tian G., Huo L., (2018) The problems and countermeasures of takeaway packaging under O2O platform [J]. Packaging Engineering, 39 (19): 144-149.

7. Zou X., Li Y., (2016) Construction of Express Packaging Recovery System Based on Circular Economy Theory [J]. Journal of Packaging, 8 (04): 60-66.

8. Lu X., Chen X., (2014) A Summary of Research on Circular Economy Theory [J]. China Population, Resources and Environment, 24 (S2): 204-208. 